\title{
Phenotypic and genetic consequences of size selection at the larval stage in the Pacific oyster (Crassostrea gigas)
}

\author{
Nicolas Taris ${ }^{a}$, Bruno Ernande ${ }^{b}$, Helen McCombie $^{c}$ and Pierre Boudry ${ }^{a_{*}}$

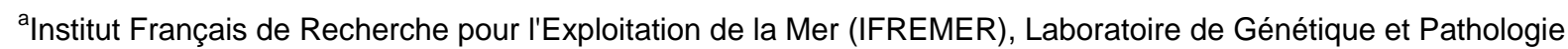 \\ (LGP), 17390 La Tremblade, France \\ ${ }^{b}$ Institut Français de Recherche pour l'Exploitation de la Mer (IFREMER), Laboratoire Ressources Halieutiques, \\ Avenue du Général de Gaulle, B.P. 32, 14520 Port-en-Bessin, France \\ ${ }^{\mathrm{c} E x p e r i a n c e, ~} 32$ avenue Albert Einstein, 17000 La Rochelle, France \\ *: Corresponding author : Tel.: +33 5467626 30; fax: +33 5467626 11. Pierre.Boudry@ifremer.fr
}

\begin{abstract}
The life histories of oysters in the genus Crassostrea, like those of most marine bivalves, are typified by high fecundity and low survival in nature. Rearing conditions in hatcheries however ensure optimized density, diet, and temperature. Hatcheries are becoming increasingly important for the production of juveniles in aquaculture, and their culture practices often include culling of slow growing larvae to reduce and synchronize the time taken to reach settlement. Because previous studies have found substantial genetic variation for early life developmental traits in Crassostrea gigas, these culling practices are likely to cause highly different selective pressures in hatcheries from those in the natural environment. We studied the phenotypic and genetic impact of such culling practices in a factorial cross between 10 males and 3 females subjected to progressive culling of the smallest $50 \%$ of larvae, compared with a non-culled control. Measurements were made on larval growth, survival, time taken to attain pediveliger stage and settlement success. Culling had a larger effect on the variance of these larval traits than on their means. The larvae in culled cultures were approximately $10 \%$ larger than those in controls, whereas the coefficient of variation was reduced by $30-40 \%$. Culling also reduced the mean time to settlement by $12 \%$ and its variance by $55 \%$. Using a multiplexed set of microsatellite markers to trace parentage, we also estimated the variance in reproductive success in a controlled experiment to quantify the consequences of intensive hatchery rearing practices. We also focused on changes in effective population size and genetic structure over time (and developmental stages). Our results show a loss of genetic diversity following removal of the smallest larvae by culling, as well as temporally varying genetic structure of the larval population. This supports the existence of genetic variability in early life developmental traits in C. gigas. Culling in hatcheries, like size-related selective pressures in the wild, are likely to have a significant genetic impact, through their effects on the timing of settlement.
\end{abstract}

Keywords: Crassostrea gigas; Culling; Genetic diversity; Hatchery; Larvae; Oysters 


\section{Introduction}

The life cycles of most benthic marine invertebrates include a pelagic larval phase. Different theories have been proposed for the evolutionary emergence of these complex life cycles. The larval stage could result from an adaptation to dispersal and habitat selection, while the adult stage represents specialization in growth and reproduction (Wray and Raff, 1991; Moran, 1994). Wilbur (1980) insists on the importance of metamorphosis, interpreting this point in complex life cycles as an adaptive size-specific shift in ecological niche.

The high fecundity of species such as elm trees and oysters, that produce large numbers of propagules and broadcast them into a hostile world, is commonly viewed as an evolutionary response to intense and unpredictable mortality at early life history stages (Williams, 1975). In the wild, the percentage of marine invertebrate larvae that actually survive to adulthood is extremely low (Thorson, 1950). The larval stage is critical for most marine invertebrates, including bivalves. Experimental studies conducted at early life stages under controlled conditions can provide valuable information about larval mortality and usefully complement studies made in the wild, where experimental approaches are more difficult.

From the first in vitro oyster fertilization (Brooks, 1879) to the appearance of modern production hatcheries, bivalve culture has seen more than one hundred years of development (Helm et al., 2004). Knowledge about bivalve reproduction and rearing techniques improved greatly during the 1960s and 1970s (Matthiessen and Toner 1966; Walne, 1965, 1974; Breese and Malouf, 1975; Dupuy et al., 1977; Jones and Jones, 1983). The seminal work by Loosanoff and Davis (1963) is commonly considered to be the foundation of many experimental and commercial hatcheries (Lucas, 1981). However, larval rearing techniques and equipment still rely more on empirical concepts and experience rather than on detailed knowledge of species biology. Today, hatcheries successfully realize controlled larval development from fertilization to post-larvae for many species and the commercial production of large numbers of "spat" (immature settled shellfish). This commercial activity initially aimed at producing spat of aquacultured species for which natural recruitment was limited due to environmental factors, technical difficulties or over-exploitation (Lucas, 1981). More recently, this activity has offered the possibility to produce genetically improved stocks through selective breeding programs or the production of triploid spat (Gosling, 2003). The Pacific oyster, Crassostrea gigas, is the most economically important bivalve species in the world. In 2002, the worldwide production reached 4.2 million metric tonnes (FAO, 2003). The proportion of spat produced by hatcheries is increasing continually. This is notably because of increasing interest in triploids (Nell, 2002) and, more recently, selective breeding (Langdon et al., 2003; Boudry et al., 2004).

In this species, as in many other bivalves, larvae and spat exhibit high phenotypic variation, particularly in terms of growth rate and survival. For instance, Collet et al. (1999) observed that for larvae reared in common trophic and thermal $\left(23^{\circ} \mathrm{C}\right)$ conditions, the first pediveliger larvae appeared 17 days post-fertilization and the last ones 26 days post-fertilization. Newkirk (1981) pointed out the unpredictability of growth rates in juvenile oysters due to high phenotypic variability, even under common environmental conditions. Larvae and spat from both hatcheries and natural recruitment have variable and usually low survival rates (Jones and Jones, 1983; Haws et al., 1993; Robert and 
Gérard, 1999). In addition, phenotypic plasticity has been shown to contribute to the variability in early life history traits in oysters (larval growth and survival: Abdel-Hamid et al., 1992; Lemos et al., 1994, morphology: Strathmann et al., 1993) depending on environmental conditions.

Furthermore, high mortality in early life can result in high variability in reproductive success between different individuals within both natural populations (Hedgecock, 1994; Li and Hedgecock, 1998) and hatchery-propagated stocks (Lannan 1980; Boudry et al., 2002). This high variability in reproductive success combined with the influence of highly variable environmental conditions which these animals encounter (Sgrò and Hoffmann, 2004), could counteract the high genetic polymorphism expected in this species due to its very high fecundity (25-50 million oocytes per female per year) and very large population sizes.

In this paper we studied the impact of selection for fast growing larvae, by culling, on phenotypic and genetic variability in the Pacific oyster, Crassostrea gigas. Culling the smallest (i.e., slowest growing) larvae to reduce the duration of larval rearing and variation in the size of spat is a common practice in bivalve hatcheries (Bardach et al., 1972). Low effective population size has often been reported in hatchery-propagated $C$. gigas stock (Hedgecock and Sly, 1990; Hedgecock et al, 1992) but the relative impact of intensive rearing practices such as culling compared with other factors (e.g., number of spawning parents) requires more examination (Laing and Earl, 1998).

To monitor the effects of selection for fast growing larvae on variability in growth rates and genetic diversity, we studied a larval population produced from a factorial cross. We used a mixed-family approach to any reduce confounding of environmental and genetic effects (Herbinger et al., 1999) and compared two different rearing practices. In one treatment the smallest larvae were progressively discarded by sieving, whereas in the other the whole larval population was maintained. As soon as the larvae were ready to settle (the pediveliger stage), samples were taken for genetic analysis. Our experiment therefore aimed (i) to quantify the effect of selecting fast growing larvae on the genetic heterogeneity of the larval population and developmental rate (i.e., age at settlement), and (ii) to evaluate the effect of selecting fast growing larvae on the effective population size of successive settlement cohorts. 


\section{Materials and Methods}

\subsection{Parental oysters}

We collected 100 adult oysters from natural beds in Charente-Maritime, France. After a two-month conditioning period to induce sexual maturation, gill fragments were collected to determine genotypes at three microsatellite loci. Out of these 100 oysters, 10 males and 3 females were chosen for the crosses. Using a similar method to Boudry et al. (2002), we chose parental oysters that were heterozygous with alleles as different as possible from one another so as to make the subsequent pedigree tracing easier.

\subsection{Breeding design}

The factorial cross between the 10 selected males and 3 selected females was performed as follows. We first stripped sperm and eggs by opening the animals' shells, lacerating the gonad and rinsing gametes into separate beakers. We then estimated gamete concentrations using Thoma slides (for sperm) and Malassez slides (for eggs) coupled to an image processing system (SAMBA ${ }^{\text {TM }}$ IPS software). Each of the 10 males was mated with the 3 females, producing 10 half-sibs families and 30 full-sibs families. Fertilization was performed at a ratio of 100 sperm per egg, $10^{6}$ oocytes being used for each mating. A parallel sample was independently raised in small dishes to estimate the fertilization rate by the percentage of developing embryos after 24h ((number of D larvae / total number of oocytes) $\mathrm{x} 100$ ). The embryos of the different families were mixed together three hours after fertilization to optimize genetic diversity while avoiding sperm competition (Boudry et al., 2002). This embryo mixture was divided between six rearing tanks ( $5 \times 10^{6}$ oocytes/tank; 3 replicated tanks/treatment).

\subsection{Larval rearing}

Larvae were reared in six GRP (Glass Reinforced Polyester) 50-litre tanks filled with filtered sea water. The larval rearing environment was maintained at $23{ }^{\circ} \mathrm{C}$ water temperature, 28-32 \%o salinity. Larvae were fed Tetraselmis suecica and Isochrysis aff. galbana (Clone T-iso; Tahitian Isochrysis) according to a three-phase rationing plan. This provided a first phase ration for larvae from 70 to $115 \mu \mathrm{m}$, a second phase for larvae from 115 to $200 \mu \mathrm{m}$ and a third for larvae above $200 \mu \mathrm{m}$. The three phases respectively received 0.3, 1.7, and 4 cells. $\mu \mathrm{L}^{-1}$.day $^{-1}$ Tetraselmis suecica and 4, 19.3, 38.5 cells. $\mathrm{L}^{-1}$.day ${ }^{-1}$ Isochrysis aff. Galbana (T-iso). One day post-fertilization, larval concentration was reduced to 10 larvae.ml . Then, from day 1 post-fertilization to the first settlement event, two different rearing treatments were applied. Three randomly chosen 50-1 tanks were subjected to "size selection" in which the smallest larvae were progressively discarded by selective sieving, whereas for the three control tanks no selective sieving was performed (Table 1). Selective sieving was conducted progressively, according to larval growth and available mesh size of sieves (Table 1). This treatment led to the cumulative culling of $50 \%$ of the larvae over the whole rearing period.

Every $48 \mathrm{~h}$, the larvae were collected in 500-ml beakers by sieving. Population sizes (the number of larvae in each tank) were then estimated by counting larvae in 5 water samples according to the procedure described in Utting and Spencer (1991). One hundred larvae from each tank were also collected to measure maximum shell length using the SAMBA $^{\mathrm{TM}}$ IPS image processing software. 
For all six tanks, when the first pediveliger larvae able to attach to a suitable substrate were observed, the largest larvae were retained by sieving on a $220-\mu \mathrm{m}$ mesh (i.e., larval length greater than $280 \mu \mathrm{m}$ ) and transferred to raceways dedicated to settlement. All larvae retained on this sieve had reached the pediveliger stage. The remaining larval population was returned to the larval rearing tanks. Successive sieving operations were performed each day. At days 20, 25 and 28 post-fertilization, 96 of the pediveliger larvae selected for settlement were preserved in $70 \%$ ethanol for parentage analysis using microsatellite markers as described below. For each settlement cohort transferred to the settlement raceways, we estimated metamorphosis success as the ratio of the number of surviving juveniles 8 days after settlement to the number of pediveliger larvae put into the raceway. Three replicate estimates of juvenile number (= total weight of a cohort divided by the individual mean weight in that cohort) were computed for each cohort.

\subsection{Parentage analysis}

Parentage analysis for larvae and adults was carried out using three multiplexed microsatellite loci in conjunction with a simple DNA extraction protocol, described in Taris et al. (2005). Samples were run on a ABI Prism 3100 automated sequencer (Applied Biosystems) and genotypes determined by Genemapper software using the binning procedure.

For parental assignment, we used the program PAPA (Package for the Analysis of Parental Allocation) which performs parental identification based on breeding likelihood methods (Duchesne et al., 2002). The allocation parameters were the global level of transmission error $(a=0.1)$ and the distribution of transmission error over alleles $(S=6)$. These two parameters were optimized to reduce the risk of misallocation in the proceedure, as recommended by Duchesne et al (2002). Samples were analysed for parental assignment on three different dates (Fig. 2): day 20 post-fertilization, corresponding to the first settlement cohort for both conditions; day 25 post-fertilization, corresponding to the last settlement cohort for the size-selection conditions and an intermediate cohort for the control conditions; and day 28 post-fertilization, corresponding to the last settlement cohort for the control conditions.

\subsection{Data analysis}

The statistical analyses detailed below involved both fixed and random effects. Time and treatments were treated as fixed effects, whereas male, female, and replicate tank effects were treated as random, as were interactions involving both random and fixed effects (e.g., malextreatment). Normally distributed data were analysed using linear mixed models (PROC MIXED, SAS/STAT ${ }^{\circledR}$ Software, SAS Institute Inc., 1999) and binomial and Poisson data were analysed using generalized linear mixed models (SAS macro GLIMMIX; Littell et al., 1996). The GLIMMIX procedure fits statistical mixed models to data with correlations or non-constant variability where the response is not necessarily normally distributed. Significance tests were based on F-statistics for fixed effects and on likelihood ratios between sub-models for random effects, which asymptotically follow a chi-squared distribution (Littel et al., 1996).

\section{Statistical inferences for phenotypic analysis.}

The proportion of developed embryos $24 \mathrm{~h}$ post-fertilization in the independent post- 
fertilization sample served to estimate the probability of each oocyte developing to the embryo stage. This binomial data was transformed using a logit link function (Logit link :f(z) $=\log (\mathrm{z} /(1-\mathrm{z}))$; McCullagh \& Nelder, 1989). The link function is used to model responses when the dependent variable is assumed to be nonlinearly (binomial distribution) related to the predictors. This allowed us to test for the variation in fertilization success among males and females by fitting a model accounting for these two effects (male and female) and their interaction:

$$
Y_{\mathrm{ijk}}=\mu+\mathrm{mal}_{i}+\mathrm{fem}_{j}+\mathrm{rep}_{k}+\mathrm{int}_{i j}+\varepsilon_{i j k}
$$

where $Y_{i j k}$ is the fertilization success of the ith male and the $j$ th female in the $k$ th replicate, $\mu$ is the whole mean, mali is the male random effect $(i=1-10)$, fem $j$ is the female random effect $(j=1-3)$, repk is the random replicate effect, intij is the interaction between male and female effect, and $\varepsilon i j k$ is the residual.

Larval length was analysed as continuously distributed data (univariate normality was tested using the Shapiro-Wilk test), and population size (the number of larvae) was analysed as Poisson data using a log link function (Log link: $\mathrm{f}(\mathrm{z})=\log (\mathrm{z})$; McCullagh \& Nelder, 1989). For each of these three variables, the data from the entire rearing period were first analysed with time as a co-variate, treatment and replicate nested within treatments [replicate(treatment)] as effects to be tested, and all relevant interactions also examined (ANCOVA):

$$
Y_{i j}=\mu+\text { time}+ \text { treat }_{i}+\text { rep }_{j}\left\{\text { treat }_{i}\right\}+\text { time* }^{*} \text { treat }_{i}+\text { time* }^{*} \text { rep }_{j}\left\{\text { treat }_{i}\right\}+\varepsilon_{i j},
$$

where $Y_{i j k}$ is the dependant variable (larval length, coefficient of variation or population size), $\mu$ is the whole mean, repk is the random replicate effect $(j=1-3)$, time is the covariable, treat is the fixed sieving effect $(i=1-2)$ and $\varepsilon i j k$ is the residual.

In these analyses, the slope of the relationship between the covariate (time) and either larval length or population size represent direct measures of larval growth rate and cumulative survival respectively. The timextreatment interaction therefore tests for significant treatment effect on these slopes and thus provides direct tests for significant effects of treatment on larval growth and survival.

We also performed independent analyses (ANOVAs) for each measurement date, with treatment and replicate(treatment) as effects, in order to precisely assess the date when significant differences appeared between treatments:

$$
Y_{i j}=\mu+\text { treat }_{i}+\text { rep }_{j}\left\{\text { treat }_{i}\right\}+\varepsilon_{i j}
$$

where the variables are defined as above.

The coefficient of variation for larval length was analysed, to detect any significant differences between crosses at each sampling date, using a non parametric procedure (Wilcoxon-Mann-Whitney test, PROC NPAR1WAY).

Statistical inferences for genetic analysis. We analysed the parental contributions of the larval fractions retained on the different dates (pediveliger larvae selected for settlement) 
as Poisson data, using a log link function (Log link: $\mathrm{f}(\mathrm{z})=\log (\mathrm{z})$; McCullagh \& Nelder, 1989)). Initially we fitted a complete model with time as a co-variate, treatment, replicate(treatment), male, and female as effects, and all relevant interactions examined:

$$
Y_{i j k l}=\mu+\text { time }+ \text { mal }_{i}+\text { fem }_{j}+\text { treat }_{l}+\operatorname{rep}_{k}\left\{\text { treat }_{l}\right\}+\text { int }_{i j k l}+\varepsilon_{i j k l}
$$

We then fitted two more models in order to examine the treatment and time effects in detail. One of these models focused on the influence of sieving by taking the parental contribution data into account independently at each sampling date.

$$
Y_{i j k l}=\mu+\text { mal }_{i}+\text { fem }_{j}+\text { treat }_{l}+\operatorname{rep}_{k}\left\{\text { treat }_{l}\right\}+\text { int }_{i j k l}+\varepsilon_{i j k l},
$$

The second model focused on the temporal effect by considering parental contribution data for both rearing conditions over time:

$$
Y_{i j k}=\mu+\text { time }+ \text { mal }_{i}+\text { fem }_{j}+\operatorname{rep}_{k}\left\{\text { treat }_{l}\right\}+\text { int }_{i j k}+\varepsilon_{i j k} \text {, }
$$

Finally, effective population size of progenies was calculated according to Robertson (1961) where $n_{i j}$ is the observed number of offspring of male $i$ and female $j$ in a given sample:

$$
\mathrm{Ne}=\left(\sum n_{i j}\right)^{2 / \Sigma n^{2}}
$$




\section{Results}

\subsection{Larval development}

Fertilization success. Mean fertilization success of the males, estimated by the proportion of successfully developed embryos 24 hours post-fertilization, ranged from $64.1 \pm 32.4 \%$ to $69.9 \pm 33.5 \%$. Variation among females was much larger, with fertilization success at $25.3 \pm 5.8 \%, 94.8 \pm 2.9 \%$, and $82.5 \pm 6.9 \%$ for the three females. As expected from these observations, fertilization success differed significantly between females $\left(\chi^{2}=67.0\right.$ $p<0.001)$ but not between males $\left(\chi^{2}=0, p=0.99\right)$. Moreover, the interaction female $\times$ male was not significant $\left(\chi^{2}=0, p=0.99\right)$. These data allowed us to take the initial effect of gamete quality into account when estimating variance in reproductive success at later stages.

Larval traits. The size of sieve mesh used to cull the cultures, mean larval length, mean relative population size (the number of larvae relative to day 1) and the intensity of culling for all sampling dates and treatments are presented in Table 1 with their respective coefficients of variation. Since no replicate(treatment) effect was significant for the larval traits, data from the different replicates were pooled for subsequent analyses.

Our progressive culling procedure led to a mean reduction in population size of $50 \%$ (cumulative percentage of daily culling, Table 1 ) at day 17 post-fertilization, relative to the control. The proportion of larvae remaining at this stage was $46.8 \pm 9.2 \%$ for the control treatment whereas it was $30.5 \pm 5.3 \%$ for the size selection treatment. Our selective culling treatment resulted in $14.2 \%$ lower final densities (cumulative survival) than the control (Table 1, $\chi^{2}=44.5, p<0.001$ ). From this, we deduced that "natural" larval mortality (i.e., not due to culling) was $14.2 \%$ higher in the control tanks than in the size selected tanks. As would be expected, treatment (culling) was found to have a highly significant effect on the decrease in population size with time (trend of overall reduction in number of live larvae: treatment $\times$ time, $\chi^{2}=44.5, p<0.001$ ). Separate analyses performed for the different dates showed that population sizes differed significantly between treatments from day 13 post-fertilization onwards (treatment, $F=17.3, p<$ $0.001)$.

Size selection also had a significant effect on mean larval growth (treatment $\times$ time, $\chi^{2}$ $=427.2, p<0.001$ ), calculated over the larval rearing period from day 1 post-fertilization to 20 post-fertilization. ANOVAs performed for each of the different dates showed that the coefficient of variation of larval length differed significantly between treatments from day 10 post-fertilization onwards $(F=8.4, p=0.04)$. Size selection had a significant effect on larval length from day 13 post-fertilization onwards $(F=12.5, p<0.001)$. The resulting mean larval length was $222.7 \pm 16.7 \mu \mathrm{m}$ (coefficient of variation $=7.5 \%$ ) for size selection compared with $204.1 \pm 29.3 \mu \mathrm{m}$ (coefficient of variation $=14.4 \%$ ) for the control (Table 1).

For both treatments, the first pediveliger larvae appeared at day 20 post-fertilization (Fig. 1). Larval mortality was negligible after this date in all tanks. The mean time taken to reach the pediveliger stage was 21 and 24 days post-fertilization in size selected and control tanks respectively. In line with the pattern observed for the coefficient of variation for larval length, selective sieving of fast growing larvae led to less variation in 
time taken to reach the pediveliger stage: settlement occurred over 5 days in the selected group as opposed to 11 in the control. Additionally, almost $89 \%$ of pediveliger larvae appeared in only three days in the size selection conditions (day 20 to 22 postfertilization) while this was much more gradual in the control tanks (Fig.1).

The total number of larvae that reached the pediveliger stage was lower in the size selected tanks (161 727 versus 236 900) but the proportion that reached the pediveliger stage was higher (61.1 \% versus $46.8 \%$ ). Finally, we obtained higher settlement success for size selected larvae than for control larvae (61.8 $\pm 3.9 \%$ versus $48.6 \pm 16.0 \%$ ), however $15 \%$ less spat were produced from the size selected conditions than from the control due to the lower number of pediveliger larvae put to settle.

\subsection{Parental contributions and genetic diversity in settlement cohorts}

Parental assignment. Altogether, 1440 larvae sampled at days 20, 25 and 28 postfertilization were genotyped. Around $90 \%$ of these were successfully assigned to a single parental pair. Failure to assign the remaining $10 \%$ was due to DNA degradation in ethanol-preserved larvae or to human error during the initial larvae sampling, rather than assignment uncertainty (Taris et al., 2005).

Parental contributions. The temporal changes in paternal and maternal contributions (at days 20, 25 and 28 post-fertilization) are represented in Fig. 2. The corresponding statistical analyses are given in Tables 2, 3, 4 and 5. All analyses of parental contributions were performed on numbers corrected for differential fertilization success (using multiplying coefficients corresponding to familial fertilization success). Since no replicate(treatment) effect was significant in main or interaction effects of the complete model, the data corresponding to the different replicates were pooled for subsequent analysis.

Table 2 resumes the results of the complete model. The temporal trend (i.e. between settlement cohorts) in the pattern of parental contributions differed between males (male $\times$ time $\left.\chi^{2}=32.1, p<0.001\right)$ and between females (female $\times$ time $\left.\chi^{2}=14.3, p<0.001\right)$. As indicated by the significant male $\times$ time $\times$ treatment interaction $\left(\chi^{2}=4.7, p=0.03\right)$, each paternal contribution shifted differently over time depending upon the rearing conditions. The subsequent models allowed the effects highlighted by the overall model to be tested specifically. Thus, as shown in Table 3, there was no interaction between treatment and male or female at day 20 post-fertilization (malextreatment $\chi^{2}=1.3, p=0.25$; female $\times$ treatment $\chi^{2}=3.2, p=0.07$ ) meaning that there was no significant effect of sieving on parental contribution at this sampling point. In contrast, at day 25 postfertilization, the interaction between treatment and male was significant (male $\times$ treatment $\chi^{2}=5.8, p=0.016$ ) indicating that at this sampling point the sieving treatment significantly affected the relative representation of males in the surviving larval populations.

Table 4 presents analyses that specifically examine parental effects for each cohort within rearing conditions. At day 20 post-fertilization, there were significant differences in the relative contributions of the males and females within both rearing conditions. By day 25 post-fertilization, both conditions had moved towards a homogenization of parental contributions. Finally, the results presented in Table 5 reveal significant changes in male parental contributions over time, as shown by the significant interaction of time $\times$ male for both rearing conditions. Differences in female parental contributions only 
appeared in the sieved cultures.

Effective population size. Temporal variation in the genetic composition of the cohorts, estimated by their effective population size relative to its value at fertilization (i.e. equal gametic contributions between males and between females), is presented in Fig. 3. At day 20 post-fertilization, the effective population sizes were only $31.3 \%$ and $40.6 \%$ of the initial reference values for the control and size selected conditions respectively. However, at day 25 post-fertilization, effective size of the settlement cohorts had increased up to $75.2 \pm 6.4 \%$ for the control treatment and $56.5 \pm 10.9 \%$ for the cohort from size selection conditions. For day 28 post-fertilization (control tanks), the effective population size remained similar to that at day 25 post-fertilization. 


\section{Discussion}

Due to the very high fecundity of bivalves, the number of gametes is generally not a limiting factor for recruitment in the wild, or for spat production in hatcheries. Hatching rates and larval survival are often unpredictable however, despite the controlled conditions in hatcheries. This can often lead to numbers of fertilized eggs much larger than needed, and larvae are typically culled in order to reduce density during development (Lipovsky, 1984, Loosanoff and Davis, 1963). Sieving is also used to eliminate undesired particles, such as the shells of dead larvae, but the smallest live larvae are removed together with the dead ones. For all these reasons, culling (i.e. the elimination of the smallest larvae by sieving) is a common practice in bivalve hatcheries. However, the phenotypic and genetic impact of this practice had received little attention by previous studies.

\subsection{Phenotypic consequences of culling}

The effect of progressively eliminating the smallest individuals in a population according to mean larval size and its coefficient of variation, depends on the variation between individuals and its temporal stability. Unlike later life stages (e.g., Boudry et al., 2003), this phenomenon is poorly documented because larvae cannot be individually tagged. If individual growth performance varies substantially between individuals over the larval growing period, elimination of the smallest individuals in one go would not have much effect on the mean and variation of growth later on. In our experiment, the progressive culling of $50 \%$ of the larvae led to an increase in mean larval length of 24.4 $\mu \mathrm{m}(+9.7 \%)$, relative to the control conditions, and a decrease in its coefficient of variation from 11.8 to $7.3(-38.1 \%)$ at day 17. It appears therefore that size selection had a greater effect on the variance of larval length than on the mean and that it homogenized larval length and larval growth. This difference between the effect of size selection on mean larval length and on its coefficient of variation was also observed at days 13 and 15 ( $+9.1 \%$ versus $-47.9 \%$ and $+10.3 \%$ versus $-48.9 \%$ respectively). A significant difference in the coefficient of variation of larval length between the two conditions was already observed as early as day 10, before much culling had been done but by which time the difference in mesh size between the treatments was already large (60 versus 110 $\mu \mathrm{m})$. Significant differences in mean larval length and population sizes however were only observed at day 13 post-fertilization. In size selected tanks, the coefficient of variation of larval length stopped increasing at day 10 post-fertilization after reaching a maximum of 7.5. However, values in the control tanks continued to increase up to 14.4 at day 13 post-fertilization and then remained constant.

The second important effect of size selection was that the pediveliger stage was reached sooner. Similarly to larval growth, variation in the date of settlement (5 versus 11 days) was more greatly affected than the mean (21 versus 24 days: a difference of 3 days $(+14 \%))$. Because slow growing larvae reached the pediveliger stage and settled later than fast growing ones, larval growth variability and timing of the pediveliger stage are likely to be directly related. Due to high variability in larval growth rate therefore, low to moderate size selection during the larval phase can have a strong effect on variability in larval length and timing of the pediveliger stage and a smaller effect on their means.

Population density can be highly influential, having negative effects on growth and survival in many organisms (for review, see Rodriguez-Muñoz et al. 2003). In our 
experiment food was provided in sufficient quantities that it was always in excess of larval needs. This should mean that density dependant effects were negligible, which was supported in the experiment by the fact that fast growing larvae reached the pediveliger stage at the same date in both conditions (size-selected versus control).

Although $50 \%$ of the larvae were culled during larval rearing in the size selection conditions, the number of spat after settlement was only $15 \%$ less than in the control. Further studies are needed to define the optimal culling ratio that would simultaneously minimize the loss of spat and reduce variability in the timing of settlement. Our results suggest that sieving out small larvae in hatcheries saves time and only reduces production a little because the remaining larger larvae have better relative survival and settlement success.

\subsection{Genetic consequences of culling}

Monitoring and maintaining genetic variability during hatchery rearing is essential for successful hatchery management (Primmer et al., 1999). Genetic factors determine the fitness and adaptability of organisms such as shellfish (Taniguchi, 2003). Maintaining a wide range of genotypes could give a hatchery population more flexibility of response to a constantly changing environment. Reduced genetic variability in hatchery stocks has often been reported in shellfish (Gosling, 1982; Wada 1986; Dillon and Manzi 1987; Hedgecock and Sly, 1990; Paynter and DiMichele 1990; Vrijendhoek et al. 1990; Gaffney et al. 1992; Durand et al. 1993). High fecundity combined with high variability in reproductive success has been shown to result in high genetic drift (Boudry et al., 2002). Our data do not allow us to directly estimate the overall impact of culling on genetic variation in the long term. However, our results do show that culling has a significant impact on genetic variation of cohorts of larvae which are ready to settle. At day 20 post-fertilization, size selected and control tanks presented similar uneven parental contributions (i.e., the first larvae ready to settle), but this was not so much the case at day 25 post-fertilization. The genetic impact of culling during the larval stage therefore appears to be essentially mediated through its effects on the timing of settlement rather than a direct effect on parental contribution. This clearly illustrates the importance of later cohorts in minimizing the effects of genetic drift in hatchery propagated stocks and agrees with Laing and Earl (1998), who proposed that all larvae be retained for spat production. For these authors, later settled cohorts deserve attention since they can also provide spat of acceptable quality. Our study shows that these late settling cohorts are important for minimizing the variability in reproductive success and therefore maximizing the overall genetic variability of a hatchery propagated population.

Culling might also have a direct genetic effect by selecting fast growing genotypes at the larval stage, although such selective processes caused by intensive hatchery practices have rarely been questioned. Ernande et al. (2003) investigated genetic variability and genetic correlations in early life-history traits of Crassostrea gigas. According to these authors, genetic polymorphism in early life-history seems to range between two extreme genetically-based "strategies": (1) fast growing larvae settling large but experiencing low settlement success and slow growth and survival after settlement, and (2) slow growing larvae settling small but experiencing higher settlement success and better growth and survival after settlement. On a population with these extremes, size selection by culling slow growing larvae would lead to reduced settlement success, and reduced growth and 
survival after settlement. However, positive phenotypic relationships were shown between larval and spat growth in both C. virginica (Newkirk et al.,1977) and C. gigas (Collet et al., 1999). Our present results also support a positive phenotypic relationship between larval growth, survival and settlement success, and show that genetic variability exists for these traits in $C$. gigas. Further studies are required to validate the genetic correlations observed by Ernande et al. (2003) between early life history traits and to investigate the mechanisms responsible for their reversal at the phenotypic level. Comparisons of early stage developmental traits between domesticated stocks (i.e., hatchery propagated populations that have been isolated for several generations) and wild populations would help to determine if differential selection occurs in hatcheries.

\section{Conclusion}

Our experimental data support the existence of genetic variability in early life developmental traits in C. gigas. The culling of slow growing larvae therefore results in, a significant loss of diversity at the larval stage, though this common hatchery practice leads to faster settlement and better relative survival of oyster larvae. The genetic effect of this size selection is mediated through its effects on the timing of settlement. This relationship suggests how our results also apply to effects of other size-related selective pressures existing in the wild. 


\section{Acknowledgements}

This work was partially funded by the BRG (Bureau des Ressources Génétiques) and the Ministère de l'Ecologie et du Développement Durable (Convention $\left.n^{\circ} 14-C / 2003\right)$. The authors wish to thank the IFREMER hatchery team in La Tremblade for technical assistance during the larval and post-larval rearing and, more specially, Pascal Phélipot. We thank Mark Camara for improving this paper and two anonymous referees for useful comments and suggestions.

\section{References}

Abdel-Hamid, M.E., Mona, M.H., Khalil, A.M., 1992. Effects of temperature and food concentrations on the growth of the larvae and spat of the edible oyster Crassostrea gigas (Thunberg). J. Mar. Biol. Assoc. India 34, 195-202.

Bardach, J.E., Ryther, J.H., McLarney, W.O., 1972. Aquaculture: the Farming and Husbandry of freshwater and Marine Organisms. New York, Wiley-Interscience.

Boudry, P., Collet, B., Cornette, F., Hervouet, V., Bonhomme, F., 2002. High variance in reproductive success of the Pacific oyster (Crassostrea gigas, Thunberg) revealed by microsatellite-based parentage analysis of multifactorial crosses. Aquaculture 204, 283296.

Boudry, P., Collet, B., Heurtebise, S., Morand, B., Gérard, A., 2003. Individual growth performance of juvenile Pacific oysters, Crassostrea gigas (Thunberg): stability over time and interaction with survival. Aquacult. Int. 11, 429-448.

Boudry, P., Dégremont, L., Taris, N., McCombie, H., Haffray, P., Ernande, B., 2004. Genetic variability and selective breeding for traits of aquacultural interest in the Pacific oyster (Crassostrea gigas). Bull. Aquacul. Assoc. Canada, 104, 12-18.

Breese, W.P., Malouf, R.E., 1975. Hatchery manual for the Pacific oyster. Oreg, State Univ. Sea Grant Pub.

Brooks, W.K., 1879. Abstract of observations upon fertilization of oyster eggs and embryology of American oyster. Am. J. Sci., New Haven, XVIII, 425-527.

Collet, B., Boudry, P., Thebault, A., Heurtebise, S., Morand, B., Gérard, A., 1999. Relationship between pre- and post settlement growth in the Pacific oyster Crassostrea gigas (Thunberg). Aquaculture 175, 215-226.

Dillon, R.T., Manzi, J.J., 1987. Hard clam, Mercenaria mercenaria, broodstocks: Genetic drift and loss of rare alleles without reduction in heterozygosity. Aquaculture 60, 99-105.

Duchesne, P., Godbout, M.H., Bernatchez, L., 2002. PAPA (Package for the Analysis of Parental Allocation): A computer program for simulated and real parental allocation. Mol. Ecol. Notes 2, 191-194.

Dupuy, J.L., Windsor, N.T., Sutton, C.E., 1977. Manual for design and operation of an 
oyster seed hatchery for the American oyster Crassostrea virginica, Virginica Institute of Marine Science, Special Report No 142.

Durand, P., Wada, K.T., Blanc, F., 1993. Genetic variation in wild and hatchery stocks of the black pearl oyster, Pinctada margarififera, from Japan. Aquaculture 110, 27-40.

Ernande, B., Clobert, J., McCombie, H., Boudry, P., 2003. Genetic polymorphism and trade-offs in the early life-history strategy of the Pacific oyster, Crassostrea gigas (Thunberg, 1795): A quantitative genetics study. J. Evolution. Biol. 16, 399-141.

FAO, 2003. Aquaculture production : Quantities 1950-2001. Fishstat Plus. http://www.fao.org/fi/statist/fisoft/FISHPLUS.asp\#Download

Gaffney, P.M., Davis, C.V., Hawes, R.O., 1992. Assessment of drift and selection in hatchery populations of oysters (Crassostrea virginica). Aquaculture 105, 1-20.

Gosling, E.M., 1982. Genetic variability in hatchery-produced Pacific oysters (Crassostrea gigas Thunberg). Aquaculture 26, 273-287.

Gosling, E., 2003. Bivalve Molluscs : Biology, Ecology and Culture. Blackwell Publishing, 443 pp.

Haws, M.C., DiMichele, L., Hand, S.C., 1993. Biochemical changes and mortality during metamorphosis of the Eastern oyster, Crassostrea virginica, and the Pacific oyster, Crassostrea gigas. Mol. Mar. Biol. Biotechnol. 2, 207-217.

Hedgecock, D., 1994. Does variance in reproductive success limit effective population sizes of marine organisms ? In Beaumont A.R. (ed.) Genetics and evolution of aquatic organisms. London: Chapman and Hall, 122-134.

Hedgecock, D., Sly, F., 1990. Genetic drift and effective population sizes of hatcherypropagated stocks of the Pacific oyster, Crassostrea gigas. Aquaculture 88, 21-38.

Hedgecock, D., Chow, V., Waples, R.S., 1992. Effective population numbers of shellfish broodstocks estimated from temporal variance in allelic frequencies. Aquaculture 108, 215-232.

Helm, M.M., Bourne, N., Lovatelli, A., 2004. Hatchery culture of bivalves. A practical manual. FAO, Fisheries Technical Paper No.471, Rome, 200 pp.

Herbinger, C.M., O’Reilly, P.T., Doyle, R.W., Wright, J.M., O’Flynn, F., 1999. Early growth performance of Atlantic salmon full-sib reared families reared in sigle family tanks versus in mixed family tanks. Aquaculture 173, 105-116.

Jones, G., Jones, B., 1983. Methods for setting hatchery produced oyster larvae. Marine Resources Branch, Ministry of Environment, BC, Canada. Information report 4: 94 pp. 
Laing, I., Earl, N.H., 1998. The lipid content, spatfall and subsequent growth of early and late settling hatchery-reared Pacific oyster, Crassostrea gigas Thunberg larvae. Aquac. Res. 29, 19-25.

Langdon, C., Evans, F., Jacobson, D., Blouin, M., 2003. Yields of cultured Pacific oysters Crassostrea gigas Thunberg improved after one generation of selection. Aquaculture 220, 227-244.

Lannan, J.E., 1980. Broodstock management of Crassostrea gigas I. Genetic and environmental variation in survival in the larval rearing system. Aquaculture 21, 323-336.

Lemos, M.B.N., Nascimento, I.A., De-Araujo, M.M.S., Pereira, S.A., Bahia, I., Smith, D.H., 1994. The combined effects of salinity, temperature, antibiotic and aeration on larval growth and survival of the mangrove oyster, Crassostrea rhizophorae. J. Shellfish Res. 13, 187-192.

Li, G., Hedgecock, D., 1998. Genetic heterogeneity, detected by PCR-SSCP, among samples of larval Pacific oysters (Crassostrea gigas) supports the hypothesis of large variance in reproductive success. Can. J. Fish. Aquat. Sci. 55, 1025-1033.

Lipovsky, V.P., 1984. Oyster egg development as related to larval production in a commercial hatchery. Aquaculture 39, 229-235.

Littell, R.C., Milliken, G.A., Stroup, W.W., Wolfinger, R.D., 1996. SAS system for mixed models. SAS Inst., Cary, NC.

Loosanoff, V.L., Davis, H.C., 1963. Rearing of Bivalve mollusks. Adv. Mar. Biol. 1, 1136.

Lucas, A., 1981. Le rôle du naissain d'écloserie dans la culture des bivalves en 1980. La Pêche Maritime 294-297.

Matthiessen, G.C., Toner, R.C., 1966. Possible methods of improving the shellfish industry of Martha's Vineyard, Duke’s County, Massachusetts. Mar. Res. Fund. 138 pp.

McCullagh, P., Nelder, J.A., 1989. Generalized Linear Models. Chapman and Hall: London.

Moran, N.A., 1994. Adaptation and constraint in the complex life cycles of animals. Annu. Rev. Ecol. S. 25, 573-600.

Nell, J.A., 2002. Farming triploid oysters. Aquaculture 210, 69-88.

Newkirk, G.F., Haley, L.E., Waugh, D.L., Doyle, R., 1977. Genetics of larvae and spat growth rate in the oyster Crassostrea virginica. Mar. Biol. 41, 49-52. 
Newkirk, G.F., 1981. On the unpredictability of bivalve growth rates: is a slow growing juvenile oyster a runt for life?, in : Claus, C. et al. (Ed.). Nursery Culturing of Bivalve Molluscs: Proceedings of the International Workshop on Nursery Culturing of Bivalve Molluscs Ghent, Belgium, 24-26 February 1981. European Mariculture Society Special Publication, 7, 211-218.

Paynter , K. T., DiMichele, L., 1990. Growth of tray-cultured oysters (Crassostrea virginica Gmelin) in Chesapeake Bay. Aquaculture 87, 289-297.

Primmer, C. R., Aho, T., Piironen, J., Estoup, A., Cornuet, J-M., Ranta, E., 1999. Microsatellite Analysis of Hatchery Stocks and Natural Populations of Arctic Charr, Salvelinus Alpinus, from the Nordic Region: Implications for Conservation. Hereditas 130, 277-289.

Robert, R., Gérard, A., 1999. Bivalve hatchery technology: the current situation for the Pacific oyster Crassostrea gigas and the scallop Pecten maximus in France. Aquat. Living Resour. 12, 121-130.

Robertson, A., 1961. Inbreeding in artificial selection programmes. Genet. Res. 2, 189194.

Rodríguez-Muñoz, R., Nicieza, A.G., Braña, F., 2003. Density-dependent growth of Sea Lamprey larvae: evidence for chemical interference. Funct. Ecol. 17, 403-408.

SAS Institute Inc., 1999. SAS/STAT User's Guide, Version 8, Cary, NC : SAS Institute Inc.

Sgrò, C.M., Hoffmann, A.A., 2004. Genetic correlations, tradeoffs and environmental variation. Heredity 93, 241-248.

Strathmann, R.R., Fenaux, L., Sewell, A.T., Strathmann, M.F., 1993. Abundance of food affects relative size of larval and postlarval structures of a molluscan veliger. Biol. Bull. 185, 232-239.

Taniguchi, N., 2003. Genetic factors in broodstock management for seed production. Rev. Fish. Biol. Fisher. 13, 177-185.

Taris, N., Baron, S., Sharbel, T.F., Sauvage, C., Boudry, P., 2005. A combined microsatellite multiplexing and boiling DNA extraction method for high throughput parentage analyses in the Pacific oyster (Crassostrea gigas). Aquac. Res. 36, 1-3.

Thorson, G., 1950. Reproductive and larval ecology of marine bottom invertebrates. Biol. Rev. 25, 1-45.

Utting, S.D., Spencer, B.E., 1991. The hatchery culture of bivalve mollusc larvae and 
juveniles. Lab. Leafl. MAFF Fish. Res. Lowestoft 68, 31 pp.

Vrijienhoek, R.C., Ford, S.E., Haskin H.H., 1990. Maintenance of heterozygosity during selective breeding of oysters for resistance to MSX disease. J. Heredity 81, 418-423.

Wada, K.T., 1986. Genetic variability at four polymorphic loci in Japanese pearl oysters, Pinctada fucata martensii, selected for six generations. Aquaculture 59, 139-146.

Walne, P.R., 1965. Observations on the influence of food supply and temperature on the feeding and growth of the larvae of Ostrea edulis. Min. Agric. Fish. Food, Fish. Invest., UK, Ser. II, 1-45.

Walne, P.R., 1974. Culture of Bivalve Molluscs, Fishing News (Books) Ltd. Surrey England. 189 pp.

Wilbur, H.M., 1980. Complex life cycles. Annu. Rev. Ecol. S. 11, 67-93.

Williams, G.C., 1975. Sex and Evolution. Princeton University Press, Princeton, NJ.

Wray, G.A., Raff, R.A., 1991. The evolution of developmental strategy in marine invertebrates. Trends Ecol. Evol. 6, 45-50. 
Table 1: Larval traits at each sampling day for size selection and control rearing conditions.

\begin{tabular}{|c|c|c|c|c|c|c|c|c|c|}
\hline \multirow[b]{2}{*}{ Day } & \multicolumn{2}{|c|}{ Mesh size ( $\boldsymbol{\mu m})$} & \multicolumn{2}{|c|}{$\begin{array}{c}\text { Mean maximal } \\
\text { Length } \pm \text { S.E. }(\mu \mathrm{m})\end{array}$} & \multicolumn{2}{|c|}{$\begin{array}{l}\text { Coefficient of } \\
\text { variation }\end{array}$} & \multicolumn{2}{|c|}{$\begin{array}{c}\text { \% larvae / initial } \\
\text { number at day } 1 \pm \text { S.E. }\end{array}$} & \multirow[t]{2}{*}{$\begin{array}{l}\text { Proportion } \\
\text { culled (\%) }\end{array}$} \\
\hline & (1) control & (2) size selection & (1) control & (2) size selection & (1) control & (2) size selection & (1) control & (2) size selection & \\
\hline 1 & 45 & 45 & $75.9 \pm 2.3$ & $75.4 \pm 2.2$ & 3.0 & 3.0 & 100 & 100 & l \\
\hline 3 & 45 & 45 & $85.6 \pm 2.9$ & $85.5 \pm 2.9$ & 3.4 & 3.4 & $85.1 \pm 12.6$ & $81.2 \pm 4.0$ & / \\
\hline 6 & 45 & 60 & $113.9 \pm 6.6$ & $113.3 \pm 6.6$ & 5.8 & 5.9 & $67.3 \pm 12.0$ & $69.2 \pm 8.9$ & $4 \pm 1$ \\
\hline 8 & 45 & 85 & $129.1 \pm 9.1$ & $130.1 \pm 6.9$ & 7.1 & 5.3 & $59.6 \pm 13.8$ & $58.4 \pm 1.1$ & $9 \pm 2$ \\
\hline 10 & 60 & 110 & $158.6 \pm 13.8$ & $163.8 \pm 11.5$ & 8.7 & 7.0 & $55.5 \pm 10.3$ & $56.4 \pm 0.9$ & $3 \pm 1$ \\
\hline 13 & 60 & 150 & $204.1 \pm 29.3$ & $222.7 \pm 16.7$ & 14.4 & 7.5 & $57.2 \pm 11.8$ & $43.3 \pm 4.2$ & $18 \pm 3$ \\
\hline 15 & 60 & 180 & $233.6 \pm 32.0$ & $257.7 \pm 18.1$ & 13.7 & 7.0 & $49.3 \pm 11.7$ & $32.0 \pm 0.4$ & $16 \pm 6$ \\
\hline 17 & 60 & 180 & $250.8 \pm 29.6$ & $275.2 \pm 19.9$ & 11.8 & 7.3 & $46.8 \pm 9.2$ & $30.5 \pm 5.3$ & 0 \\
\hline
\end{tabular}


Table 2: Results of overall GLIMMIX model including all effects.

\begin{tabular}{lll}
\hline Fixed effects & F value & Pr $>$ F \\
\cline { 2 - 3 } Treatment & 0.00 & 0.9775 \\
Day & 1.10 & 0.4853 \\
& & \\
\cline { 2 - 3 } Random effects & Chi $^{2}$ & P value \\
\cline { 2 - 3 } Day x Male x Female x Treatment & 10.4 & $0.001^{* * *}$ \\
Day x Treatment x Male & 4.7 & $0.030 *$ \\
Day x Treatment x Female & 0 & 1.000 \\
Treatment x Male & 1.6 & 0.206 \\
Treatment x Female & 0 & 1.000 \\
Male x Female & 8.86 & $0.003 * *$ \\
Day x Male & 32.1 & $0.000 * * *$ \\
Day x Female & 14.3 & $0.000 * * *$ \\
Day x Treatment & 0.1 & 0.752 \\
Male & 32.3 & $0.000 * * *$ \\
Female & 10.3 & $0.001 * * *$ \\
\hline
\end{tabular}


Table 3: Results of the GLIMMIX sub-model focusing on the treatment (sieving) effect by taking into account the parental contribution data independently at each sampling date.

\begin{tabular}{|c|c|c|c|c|}
\hline & \multicolumn{2}{|l|}{ Day 20} & \multicolumn{2}{|l|}{ Day 25} \\
\hline & F value & $\operatorname{Pr}>\mathrm{F}$ & F value & $\operatorname{Pr}>F$ \\
\hline \multirow[t]{2}{*}{ Treatment } & 0.23 & 0.67 & 0.15 & 0.73 \\
\hline & $\mathrm{Chi}^{2}$ & $P$ value & $\mathrm{Chi}^{2}$ & $\mathrm{P}$ value \\
\hline Treatment x Male x Female & 7.1 & $0.008 * *$ & 3.3 & 0.069 \\
\hline Male x Treatment & 1.3 & $0.254 \mathrm{~ns}$ & 5.8 & $0.016 *$ \\
\hline Female x Treatment & 3.2 & 0.07 & $\sim 0$ & 0.99 \\
\hline Male x Female & 37.2 & $<0.001 * * *$ & $\sim 0$ & 0.99 \\
\hline Male & 28.6 & $<0.001 * * *$ & 20.4 & $<0.001 * * *$ \\
\hline Female & 10.4 & $0.001 * *$ & $\sim 0$ & 0.99 \\
\hline
\end{tabular}


Table 4: Results of GLIMMIX sub-model focusing on male and female effect for both rearing conditions at each sampling date.

\begin{tabular}{|c|c|c|c|c|c|c|c|}
\hline & & \multicolumn{2}{|c|}{ Day 20} & \multicolumn{2}{|c|}{ Day 25} & \multicolumn{2}{|c|}{ Day 28} \\
\hline & & $\mathrm{Chi}^{2}$ & $\mathrm{P}$ value & $\mathrm{Chi}^{2}$ & $\mathrm{P}$ value & $\mathrm{Chi}^{2}$ & P value \\
\hline \multirow[t]{2}{*}{ Size Selection } & Male & 16.7 & $<0.001 * * *$ & $\sim 0$ & 0.99 & ----- & ----- \\
\hline & Female & 30.3 & $<0.001 * * *$ & 1.1 & 0.294 & ----- & ----- \\
\hline \multirow[t]{2}{*}{ Control } & Male & 8.3 & $0.004 * *$ & 274 & $<0.001 * * *$ & 17.9 & $<0.001 * * *$ \\
\hline & Female & 4.2 & $0.04 *$ & 1.6 & 0.206 & $\sim 0$ & 0.99 \\
\hline
\end{tabular}


Table 5: Results of GLIMMIX sub-model focusing on temporal effect considering contribution data for both rearing conditions over time.

\begin{tabular}{|c|c|c|c|c|}
\hline & \multicolumn{2}{|l|}{ Control } & \multicolumn{2}{|c|}{ Size selection } \\
\hline & F value & $\operatorname{Pr}>F$ & F value & $\operatorname{Pr}>\mathrm{F}$ \\
\hline \multirow[t]{2}{*}{ Time } & 0.43 & 0.57 & 0.64 & 0.57 \\
\hline & $\mathrm{Chi}^{2}$ & $P$ value & $\mathrm{Chi}^{2}$ & $P$ value \\
\hline Time x Male x Female & 10.5 & 0.001 & 12.5 & $<0.001 * * *$ \\
\hline Male x Time & 29.9 & $<0.001 * * *$ & 6.6 & $0.01 * *$ \\
\hline Female $x$ Time & 3.3 & 0.069 & 20.6 & $<0.001 * * *$ \\
\hline Male x Female & 7.1 & $0.008 * *$ & 0 & 0.99 \\
\hline Male & 9.2 & $0.002 * *$ & 17.8 & $<0.001 * * *$ \\
\hline Female & 0.1 & 0.752 & 6.6 & $0.01 * *$ \\
\hline
\end{tabular}


Figure 1: Temporal evolution of the number of ready-to-settle larvae.

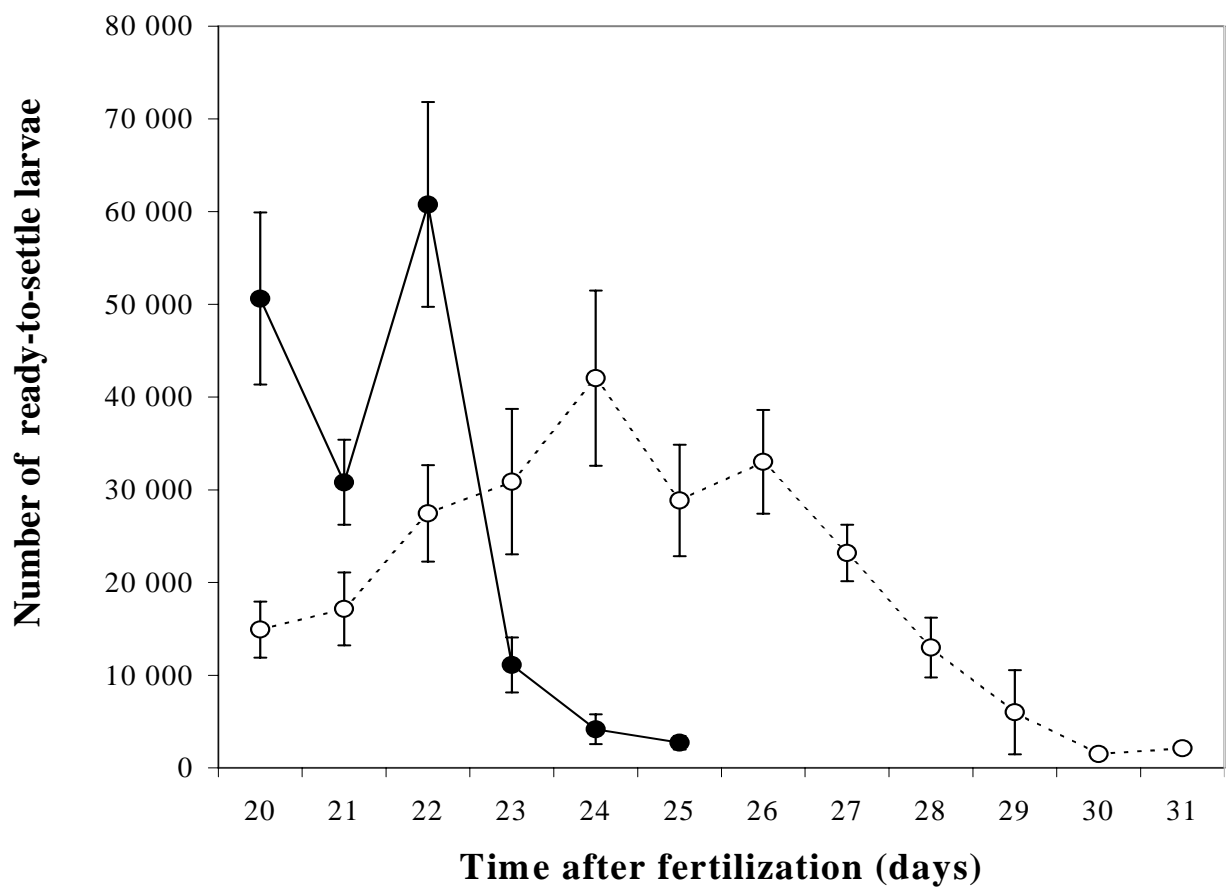

$\cdots$ O - control treatment $\longrightarrow$ size selection condition 
Figure 2: Temporal changes of relative paternal (left) and maternal (right) contributions (black bars: size selection conditions, white bars: control).
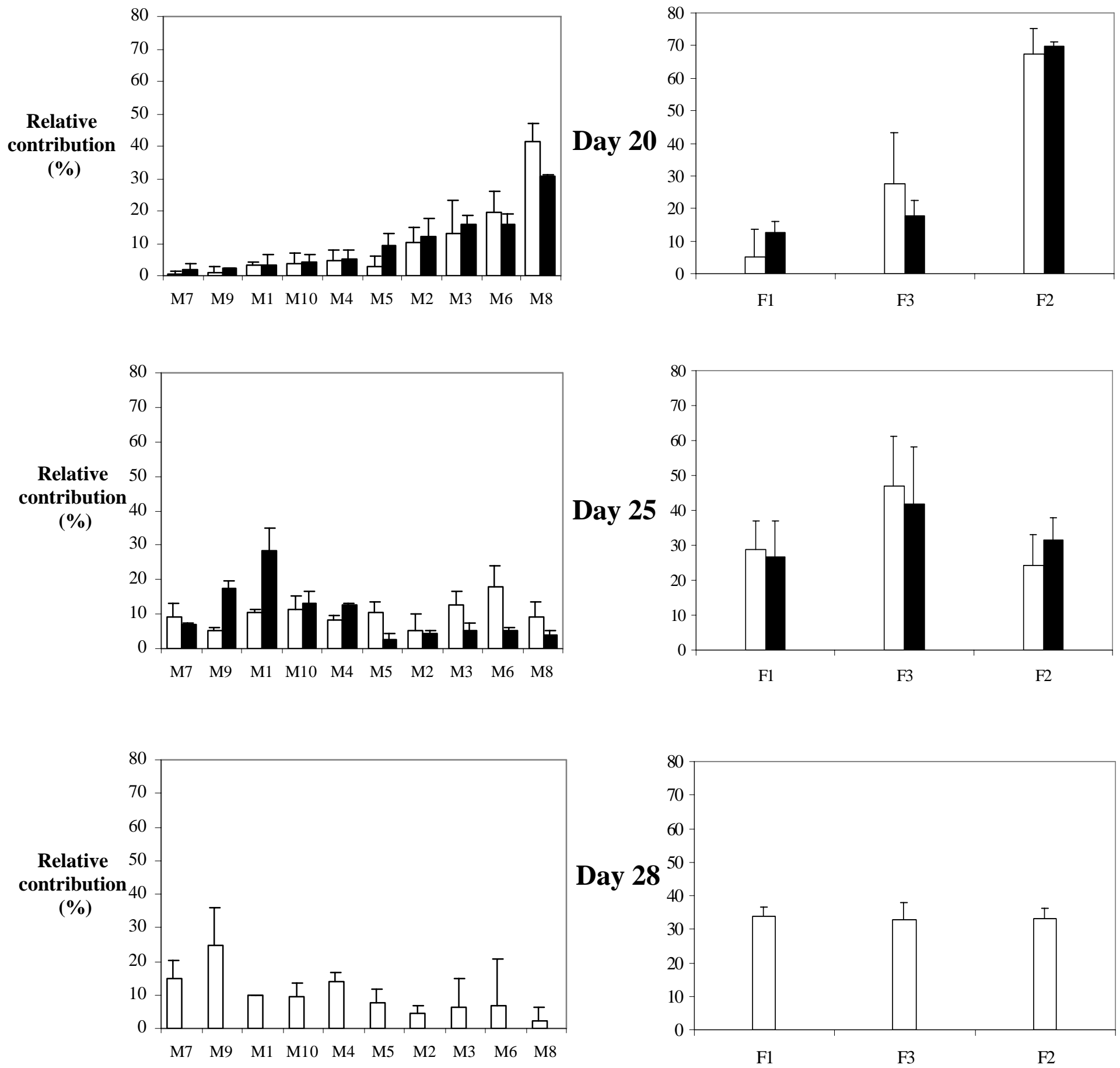
Figure 3: Evolution of effective population size, expressed as the percentage of the initial value at fertilization.

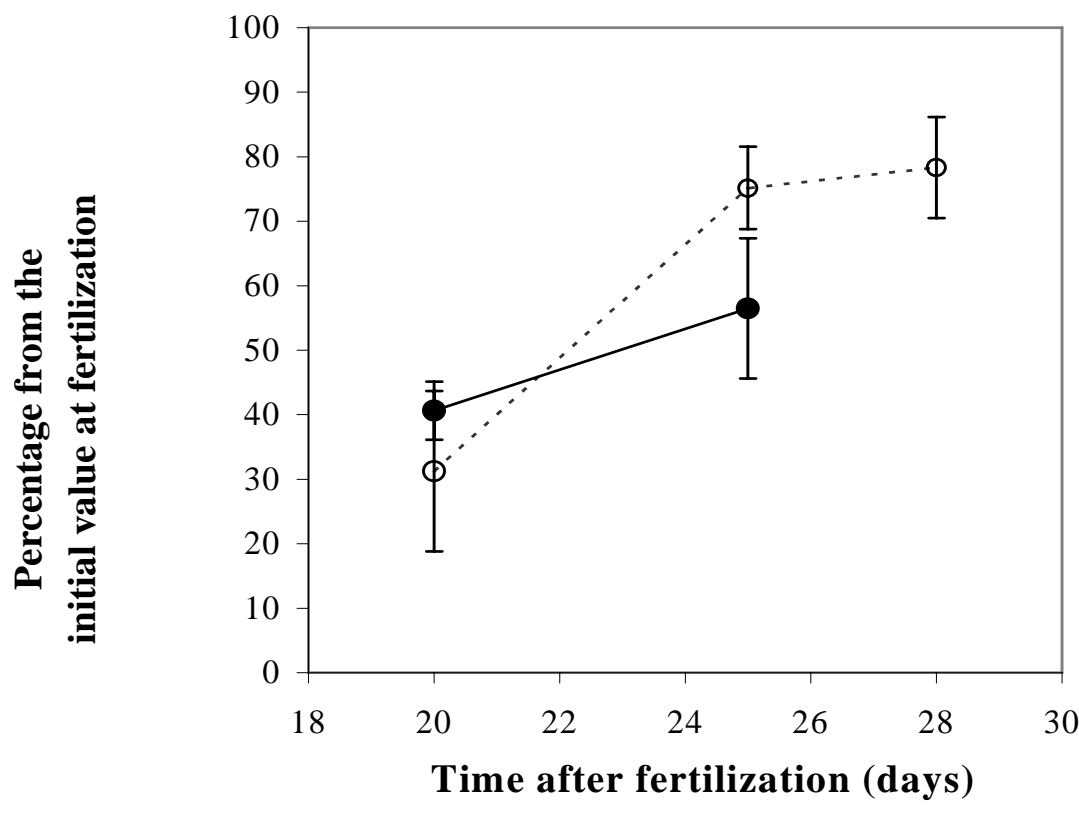

$\cdots \circ \cdots$ control treatment $\longrightarrow$ - size selection condition 